\title{
O piso salarial profissional nacional, a política de fundos e o vencimento dos profissionais do magistério público estadual de educação básica de Santa Catarina ${ }^{1}$
}

The national professional minimum wage, the political funds and the payment of public state teaching professionals in Santa Catarina, Brazil basic education in Santa Catarina

\author{
El salario profesional nacional, los fondos y los salários de \\ los professionales de enseñanza de la educación básica en \\ Santa Catarina
}

\section{Maria da Graça Nóbrega Bollmann² Marcos Edgar Bassi ${ }^{3}$}

\section{Resumo}

O artigo analisa a trajetória do vencimento dos profissionais do magistério público estadual da educação básica de Santa Catarina entre 1995 e 2014 no contexto da política de fundos e da implantação do piso salarial profissional nacional. As análises quantitativa e documental realizadas nesse contexto, sobre os dados do quadro do magistério disponibilizados pela Secretaria do Estado da Educação e sobre os valores dos vencimentos extraídos das tabelas de vencimentos do magistério publicadas na legislação estadual, permitiram a constatação de significativas alterações, tanto na composição do quadro do magistério quanto na trajetória do valor dos seus vencimentos ao longo do período. A maioria dos profissionais do magistério progrediu para o nível de Pós-Graduação em grau de Especialização, próximo do topo da carreira, nos valores mais elevados de vencimentos. A trajetória dos vencimentos, por sua vez, mostra desvalorização nos anos iniciais do período, estabilização nos anos intermediários com baixos valores e valorização real apenas com o cumprimento da lei do piso depois de ter sido confirmada a sua constitucionalidade pelo Supremo Tribunal Federal. Contudo, o governo estadual conteve a repercussão dessa valorização ao longo da carreira ao achatar a dispersão percentual entre os vencimentos, desestruturando o plano de carreira e remuneração do magistério estadual.

Palavras-chave: Política educacional; Educação básica; Valorização do magistério; Piso Salarial Profissional Nacional do Magistério; Plano de cargos, carreira e remuneração.

\footnotetext{
10 artigo é um dos resultados da pesquisa "Remuneração de professores de escolas públicas de educação básica no contexto do Fundeb e do PSPN" desenvolvida em Santa Catarina, aprovada e apoiada financeiramente pelo Programa Observatório da Educação - 0BEDUC 2013, Edital $n^{0}$. 049/2012/ CAPES/INEP. Contou com a colaboração das bolsistas Franciele Vieira e Andreia Debovi, da professora Me. Gisele Vargas e do professor Dr. Waldir Luiz Schwenbger, da Universidade do Sul de Santa Catarina (Unisul).
}

2Doutorado em Educação - PUC-RJ. Professora da Universidade do Sul de Santa Catarina (UNISUL). E-mail: gracabol@uol.com.br.

3Doutor em Educação. Professor da UFSC. E-mail: marcos.e.bassi@gmail.com. 


\begin{abstract}
This work analyzes the path of the payment of public state teaching professionalsfrom basic education in Santa Catarina between 1995 and 2014, contextualized in the political funds and in the application of the national professional minimum wages. The quantitative and documental analyzes, made at that context about the data of the teaching frame available by the State Education Secretary and about the amount of the payment extracted from teaching salary grid, published in state legislation, allowed the observation of significant changes, either in the composition of teaching frame or in the trajectory of their payment value over that period. Most of the teaching professionals progressed to specialization Post Graduation level, close to the career roof, with higher wages. The payment trajectory, in this way, shows depreciation in the early years of the period, stabilization in intermediary years with low values and the real values was only with the application of the minimum salary law, after being confirmed the constitutionality by the Supreme Federal Court. However, the state government controlled the effect of that valuation through the career when it was flatten the percentage spread between the payments, disrupting the career plan and the payment for state teaching.

Keywords: Educational Policy; Basic Education; Enhancement of Teaching; Minimum.National Wage for Teachers;Career and Remuneration Plan.
\end{abstract}

\title{
Resumen:
}

El artículo analiza la trayectoria de la remuneración de los profesionales de la educación pública básica en Santa Catarina, entre 1995 y 2014 en el contexto de la política de los fondos y de la aplicación del salario profesional nacional. Las análisis quantitativa y documental de este contexto, sobre los datos de los docentes puestos a disposición por la Secretaría de Estado de Educación y los valores de los salarios extraídos de las escalas de sueldos publicados en la ley estatal permitió el hallazgo de cambios significativos tanto en magisterio de la composición de la imagen como el valor de la trayectoria de sus salarios durante el período. La mayoría de los profesionales de la enseñanza progresaron hasta el nivel de Postgrado (en Especialización), cerca de la cima de su carrera, a los salarios más altos del extremo. La trayectoria de los salarios, a su vez, muestra la depreciación en los primeros años del período, la estabilización en los años intermedios con valores bajos y un valor real sólo a la aplicación de la ley de carreteras después de haber sido confirmó su constitucionalidad por el Tribunal Supremo. Sin embargo, el gobierno del estado contenía el impacto de esta apreciación a lo largo de su carrera para aplanar el porcentaje del diferencial entre los salarios, lo que altera el plan de carrera y pagar la enseñanza estatal.

Palabras clave: Política educativa; Educación básica; Mejora de la enseñanza; Piso Salarial Profesional Nacional de los Docentes; Plan de carrera y remuneración. 


\section{Introdução}

O artigo analisa a trajetória dos vencimentos dos profissionais do magistério da rede pública estadual de educação básica ${ }^{4}$ de Santa Catarina entre 1995 e 2014. Nesse contexto, passou a vigorarna política educacional nacional, mais especificamente a partir de 1998, o que ficou conhecido comopolítica de fundos (BRASIL, 1996a; 2006). Entre esse ano e 2006 vigorou o Fundo de Manutenção e Desenvolvimento do Ensino Fundamental e de Valorização do Magistério (Fundef), que foi substituído em 2007 pelo Fundo de Manutenção e Desenvolvimento da Educação Básica e de Valorização dos Profissionais da Educação (Fundeb), cuja vigência se estenderá até 2020.

A política de fundos tem promovido uma redistribuição mais equitativa dos recursos da vinculação constitucional da receita de impostos entre o governo estadual e os governos municipais em cada unidade da federação, por meio do estabelecimento de um mesmo valor por aluno. O governo federal participa da política na complementação de fundos estaduais cujo valor por aluno é inferior ao patamar estabelecido anualmente. Na primeira versão da política de fundos, apenas o Ensino Fundamental, a etapa intermediária da educação básica, foi foco da redistribuição, não havendo, contudo, acréscimo de recursos novos, razão de muitas avaliações críticas (ARELARO, 2007; DAVIES, 2001; MONLEVADE; FERREIRA, 1998; OLIVEIRA, 2007). O Fundeb estendeu a sua cobertura a toda a educação básica, ampliou a redistribuição dos recursos da vinculação de acordo com diferenciados e acordados valores por aluno e ampliou o comprometimento financeiro do governo federal com a complementação para um maior número de fundos estaduais. Esse acréscimo de recursos novos, entretanto, permaneceu distante da histórica insuficiência de recursos e da redução das desigualdades educacionaisintra e entre os estados brasileiros (MARTINS, 2011; DAVIES, 2008).

Entre os vários mecanismos de redistribuição e destinação dos recursos introduzidos pela política de fundos no financiamento da educação pública interessa-nos aqui destacar aqueles mais diretamente relacionados à valorização do magistério. Assim, nas duas versões dos fundos é declarado o objetivo da remuneração condigna do magistério e dos trabalhadores da educação, respectivamente. Para isso, pelo menos $60 \%$ da receita recebida pelos estados e municípios dessa fonte deveriam ser aplicados no pagamento dos professores do Ensino Fundamental no Fundef e dos profissionais do magistério da educação básica no Fundeb (BRASIL 1996c; 2006).

No que ser refere à remuneração propriamente dita, a lei regulamentadora do Fundef (BRASIL, 1996c) definiu que os governos estaduais e municipais e o Distrito Federal dispusessem de novos planos de carreira e remuneração especificamente para os professores do Ensino Fundamental, de acordo com diretrizes específicas a serem estabelecidas pelo Conselho Nacional de Educação (CNE). Nesse aspecto, o CNE emitiu dois pareceres, o primeiro deles (BRASIL, 1997a) retomava as indicações do Pacto pela Valorização do Magistério e Qualidade da Educação e defendia claramente a adoção por meio de lei federal de um piso salarial profissional nacional $(\mathrm{PSPN})^{5}$, o que contrariava a orientação política e econômica do governo federal. Rejeitado pelo Ministro da Educação Paulo Renato Souza, à época, o CNE emitiu um segundo parecer, cuja resolução então homologada (BRASIL, 1997b) não faz nenhuma menção ao PSPN, mas apenas a uma remuneração média mensal docente, sem estipular qualquer valor. Digna de nota é a indicação de que a remuneração do professor com titulação em licenciatura plena não ultrapasse em mais de 50\% a remuneração do professor com titulação de ensino médio.

No Fundeb, os mecanismos relativos à remuneração do magistério são mais claros e evidentes no texto da própria Emenda Constitucional (EC53). O inciso V, art. 206, da Constituição Federal de 1988, por exemplo, que estabelecia o princípio da valorização do magistério, foi dividido em dois, sendo destacada em um inciso únicoa referência ao PSPN. Segundo Abicalil (2008), essa foi uma das alterações na legislação que contornaram um dos

40 destaque ao magistério da educação básica se faz necessário para diferenciá-lo do magistério da educação superior que atua em várias unidades da Universidade Estadual de Santa Catarina (UDESC), não considerado neste artigo.

5 Parecer elaborado pelo conselheiro João Antônio Cabral de Monlevade. 
entraves que impediam a concretização do PSPN. Por fim, a EC53 determinou que lei específica estabelecesse o PSPN. A lei que regulamentou o Fundeb (BRASIL 2007), além de determinar prazo de um ano para a fixação da lei do PSPN, estabeleceu que os estados, os municípios e o Distrito Federal implantassem planos de carreira e remuneração para os profissionais da educação básica.

O PSPN foi finalmente instituído em 2008 (BRASIL, 2008), com valor inicial mínimo de R\$950,00, especificamente para o vencimento inicial dos profissionais do magistério com formação de ensino médio modalidade normal em jornada de 40 horas semanais, das quais no máximo 2/3 deveriam ser destinadas a atividades junto aos alunos, reservando 1/3 restante à hora atividade. A lei também estabeleceu que o valor do piso deveria ser corrigido no início de cada ano, de acordo com o mesmo percentual de crescimento do valor anual mínimo por aluno do Ensino Fundamental urbano do Fundeb. As correções havidas têm sido sempre superiores à inflação do período, o que tem assegurado se cumpridas, a real valorização do vencimento inicial das carreiras do magistério. Em 2010, a correção foi de 7,86\%; em 2011, 15,85\%; em 2012, 22,22\%; em 2013, 7,97\%; em 2014, 8,43\%; e em 2015, 13,01\% (BASSI; GIL, 2015).

A resolução do CNE que fixou as novas diretrizes nacionais para os planos de carreira e remuneração ratifica esses aspectos do PSPN (BRASIL, 2009). A lei do PSPN, quase imediatamente à sua aprovação, foi alvo de Ação Direta de Inconstitucionalidade (ADIn) n 4.167 (BRASIL, 2011) junto ao Supremo Tribunal Federal (STF), apresentada pelos governadores de cinco estados, com a alegação, entre outras, de que a lei do piso extrapolaria seu alcance ao definir o piso como vencimento básico e não como remuneração total, intervindo assim no que seria uma das prerrogativas dos entes federados (SILVEIRA, 2013; BASSI, GIL, 2015). Até o julgamento definitivo em 2011, a implementação efetiva da lei foi sendo protelada. Convém ressaltar que o governador do Estado de Santa Catarina foi um dos proponentes da ADIn ${ }^{6}$. A confirmação da constitucionalidade da lei do piso pelo STF, seguida de mobilização, greves e paralizações dos professores em todo o Brasil, forçou os governadores e prefeitos ao cumprimento da lei.

Em suma, tendo em vista a sua inserção o PSPN como um dos princípios constitucionais da educação nacional em 1988, a sua materialização em lei, e na prática foi protelada por mais de 20 anos. Até a sua exigência em lei, o PSPN permanecia apenas como bandeira de lutas da Confederação Nacional dos Trabalhadores em Educação (CNTE), dos sindicados do magistério a ela associados e de setores favoráveis à efetiva valorização do magistério.

A reconstituição do contexto das políticas e da legislação em torno da remuneração do magistério, em geral, e do PSPN, em particular, possibilita, a seguir, a análise da trajetória dos vencimentos dos profissionais do magistério da rede pública estadual de educação básica de Santa Catarina. O foco nos vencimentos requer, entretanto, um breve esclarecimento. Ao se deter sobre o significado conceitual dos termos "salário", "vencimento" e "remuneração", Camargo et al (2009, p. 342) esclarecem que "No caso do magistério público, a remuneração é composta pelos vencimentos do cargo, acrescida de vantagens pecuniárias permanentes estabelecidas em lei [...]". Assim, muito embora acima tenha havido freqüentes menções à remuneração, a análise aqui empreendida deter-se-á sobre os vencimentos que, de modo geral, é o principal componente daquela.

Antes da análise dos vencimentos é necessário situar a quantidade de profissionais do magistério estadual, a sua composição, bem como o seu enquadramento na carreira no período, o que vai ajudar, posteriormente, na verificação do alcance e implicações do PSPN na estrutura da carreira e ao longo dos seus níveis, classes e referências.

Procedeu-se a uma análise quantitativa e documental. As informações sobre o quadro do magistério foram disponibilizadas pela Secretaria Estadual da Educação (SED) e obtidas no site da Secretaria de Estado da Fazenda. Os dados sobre os vencimentos do período foram extraídos das tabelas de vencimentos do magistério, cedidas pela SED, pelo Sindicato dos Trabalhadores em Educação de Santa Catarina (SINTE) e copiados da legislação disponível no site da Assembleia Legislativa do Estado de Santa Catarina (ALESC).

6 Além dos governadores de Santa Catarina e do Mato Grasso do Sul, assinaram a ADIn os governadores do Rio Grande do Sul, do Paraná e do Ceará. 


\section{Os profissionais do magistério público estadual e seus vencimentos}

O quadro do magistério público estadual catarinense descrito na Tabela 1 passou por significativas alterações entre 2004 e 2014. Nesse intervalo foi criado o cargo de Assistente de Educação para funções administrativas nas unidades escolares. Junto aos cargos de Professor, de Especialista em Assuntos Educacionais ${ }^{7}$, de Consultor Educacional e de Assistente Técnico Pedagógico, compõe o quadro efetivo estatutário, cujos ocupantes ingressam por meio de concurso público (SANTACATARINA, 1992; 2005). O quadro do magistério é complementado por um número significativo de professores Admitidos em Caráter Temporário (ACT) que, como o próprio nome indica, são profissionais contratados temporariamente por cerca de 10 (dez) meses a cada ano para o exercício da docência, após processo seletivo específico. Note-se que os ACT superaram numericamente os professores, alcançando, em 2014, praticamente a metade do quadro efetivo. Tal destaque é importante, como será visto adiante, pois o valor do vencimento desses professores contratados, ao apresentar certa proporcionalidade em relação ao dos efetivos, será beneficiado com a implantação do PSPN e terá peso decisivo no volume da despesa total com os vencimentos.

Com relação aos profissionais efetivos ${ }^{8}$ chama a atenção a queda significativa no número de Professores, seguida da redução do número de Especialistas em Assuntos Educacionais e de Consultores Educacionais, enquanto Assistentes Técnicos Pedagógicos e Assistentes de Educação mostra crescimento expressivo. A redução do número dos primeiros pode ser atribuída às aposentadorias, combinada com a ausência de concursos públicos, como é atestado pelo volumoso e crescente número de ACT particularmente para ocupar as vagas dos Professores aposentados. Observe-se que a quantidade e a proporção de redução dos Professores são praticamente compensadas pelo crescimento do número e proporção dos ACT. Esse quadro indica a adoção pelo governo estadual de política de contenção das despesas com a folha de pagamentos e de controle da atuação do magistério (BORGES, 1995).

Tabela 1 - Magistério público estadual de educação básica -cargos, composição e evolução quantitativa-2004-2014 (mês de referência: outubro)

\begin{tabular}{|lrrrrr|}
\hline \multirow{2}{*}{ Cargos } & \multicolumn{2}{c}{2004} & & 2014 & Variação \% \\
\cline { 2 - 5 } & \multicolumn{1}{c}{$\mathrm{n}^{\mathrm{o}}$} & $\%$ & $\mathrm{n}^{\mathrm{o}}$ & $\%$ & $2004-2014$ \\
\hline Professor & 21.492 & $52 \%$ & 17.812 & $42 \%$ & $-17 \%$ \\
Especialista em Assuntos Educacionais & 1.880 & $5 \%$ & 1.018 & $2 \%$ & $-46 \%$ \\
Consultor Educacional & 145 & $0,4 \%$ & 66 & $0,2 \%$ & $-54 \%$ \\
Assistente Técnico Pedagógico & 50 & $0,1 \%$ & 1.870 & $4 \%$ & $3640 \%$ \\
Assistente de Educação & - & - & 1.203 & $3 \%$ & - \\
Professor ACT & 17.632 & $43 \%$ & 20.823 & $49 \%$ & $18 \%$ \\
\hline Total & $\mathbf{4 1 . 1 9 9}$ & $\mathbf{1 0 0} \%$ & $\mathbf{4 2 . 7 9 2}$ & $\mathbf{1 0 0 \%}$ & $\mathbf{4 \%}$ \\
\hline
\end{tabular}

Fonte: Os autores com base em Santa Catarina(2011a; 2014).

Legenda: Professor ACT = Professor Admitido em Caráter Temporário.

70 Especialista em Assuntos Educacionais acumula as funções de administrador, supervisor e orientador escolar.

8 Profissionais efetivos são os cargos em que o ingresso na carreira ocorre por concursos públicos de provas e títulos, também chamados de estatutários. 
Os ocupantes dos cargos efetivos do magistério movimentam-se ao longo de carreira que está estruturada verticalmente em 4 (quatro) níveis de acordo com a formação dos profissionais do magistério (Magistério - Ensino Médio; Graduação com Licenciatura Curta; Graduação com Licenciatura Plena e Pós-Graduação), cada um deles dividido em 3 (três) subníveis, somando ao todo 12 subníveis numerados. Cada subnível do nível Pós-Graduação, em particular, corresponde, respectivamente, à formação em Especialização, em Mestrado e em Doutorado. A progressão vertical ocorre a qualquer tempo mediante a apresentação de nova formação pelo professor. Em disposição horizontal, cada subnível compreende 7 (sete) referências ou classes, identificadas com as letras de A a G, com valores crescentes de vencimento cada uma. A progressão horizontal pode ocorrer pela conquista de duas referências a cada 3 (três) anos, uma por tempo de serviço e outra por desempenho satisfatório no exercício do cargo (SANTA CATARINA, 1992; BASSI; DEBOVI; SANDRINI, 2012).

O número e a distribuição dos profissionais do magistério em cada subnível da carreira, mostrado pela Tabela 2, enfatiza importantes alterações entre 2004 e 2010. A mais evidente é que a maioria dos profissionais progrediu na carreira para as posições mais altas na tabela de vencimentos ao adquirirem a Pós-Graduação em Especialização, movimento que já vinha ocorrendo. Assim, enquanto nos subníveis relativos à formação de Graduação em Licenciatura Plena a proporção dos profissionais reduziu-se para 15\%, no subnível imediatamente superior, correspondente a formação de pós-graduação, nível Especialização, concentravam-se $77 \%$ dos profissionais. Logo que ingressam na carreira no subnível 7, e quase que simultaneamente aos três anos exigidos de estágio probatório, os profissionais do magistério podem frequentar e concluir cursos de Especialização nas universidades privadas, cujo certificado Ihes permite progredir para o subnível 10, em uma espécie de atalho vertical na carreira. Adquirem assim rapidamente posições em classes com vencimentos superiores aos que alcançariam em maior tempo de espera se perseguissem a progressão horizontal nos subníveis 7, 8 e 9 da formação em Licenciatura Plena. Pode-se acrescentar que tal movimento foi impulsionado também devido aos baixos valores dos vencimentos nas classes dos níveis e subníveis do início da carreira.

O subnível 10 relativo à Pós-Graduação lato sensu, nível Especialização, pode ser considerado o topo possível da carreira, já que avançar aos dois subníveis superiores depende do ingresso nos poucos Programas de Pós-Graduação stricto sensu em Santa Catarina, com rigorosos processos seletivos que oferecem poucas e disputadas vagas gratuitas nas 3 (três) universidades públicas e nas demais universidades comunitárias e particulares do estado que cobram mensalidades ${ }^{9}$.

9 Em todo o Estado de Santa Catarina estão credenciados pela Coordenação de Aperfeiçoamento de Pessoal de Nível Superior (Capes) 3 programas de pós-graduação em educação com mestrado e doutorado e mais 8 apenas com mestrado. 
Tabela 2 - Distribuição dos profissionais do magistério em efetivo exercício nos subníveis da carreira 2004/2010 (mês de referência: agosto)

\begin{tabular}{|ccccccc|}
\hline & \multicolumn{2}{c}{2004} & & 2010 & Variação \% \\
\hline Habilitação & Nível & $\mathrm{n}^{\mathrm{o}}$ & $\%$ & $\mathrm{n}^{\mathrm{o}}$ & $\%$ & $2004-2010$ \\
\hline \multirow{2}{*}{ Ensino Médio } & 1 & 425 & $2 \%$ & 530 & $2 \%$ & $25 \%$ \\
Magistério & 2 & 749 & $3 \%$ & 45 & $0 \%$ & $-94 \%$ \\
& 3 & 1.192 & $5 \%$ & 171 & $1 \%$ & $-86 \%$ \\
\hline \multirow{2}{*}{ Graduação } & 4 & 190 & $1 \%$ & 44 & $0 \%$ & $-77 \%$ \\
Licenciatura Curta & 5 & 103 & $0 \%$ & 43 & $0 \%$ & $-58 \%$ \\
& 6 & 220 & $1 \%$ & 80 & $0 \%$ & $-64 \%$ \\
\hline \multirow{2}{*}{ Graduação } & 7 & $\mathbf{8 . 9 9 5}$ & $\mathbf{3 7 \%}$ & $\mathbf{3 . 0 2 7}$ & $\mathbf{1 3 \%}$ & $\mathbf{- 6 6 \%}$ \\
Licenciatura Plena & 8 & 435 & $2 \%$ & 183 & $1 \%$ & $-58 \%$ \\
\hline PG - Especialização & 10 & $\mathbf{1 0 . 5 9 0}$ & $\mathbf{4 4 \%}$ & $\mathbf{1 7 . 3 0 6}$ & $\mathbf{7 7 \%}$ & $\mathbf{6 3 \%}$ \\
PG - Mestrado & 11 & 672 & $3 \%$ & 791 & $4 \%$ & $18 \%$ \\
PG - Doutorado & 12 & 22 & $0 \%$ & 42 & $0 \%$ & $91 \%$ \\
\hline TOTAL & & $\mathbf{2 4 . 1 2 0}$ & $\mathbf{1 0 0 \%}$ & $\mathbf{2 2 . 5 6 5}$ & $\mathbf{1 0 0 \%}$ & $\mathbf{- 6 \%}$ \\
\hline
\end{tabular}

Fonte: Os autores com base em Santa Catarina (2011b).

Outra constatação que emana da Tabela 2 é que apenas 3\% dos profissionais do magistério (eram 10\% em 2004) encontravam-se nos patamares iniciais da carreira com formação de Ensino Médio - Magistério. Esse reduzido número de cargos tendentes à extinção está adequado a regulamentações estabelecidas pela Lei de Diretrizes e Bases da Educação Nacional (LDB) (BRASIL, 1996b). De um lado, os professores com essa formação não podem atuar na Educação Infantil e nas séries iniciais do Ensino Fundamental. De outro, a responsabilidade pela educação infantil passou à alçada de competência dos municípios, que dividem com os governos estaduais a responsabilidade pelo Ensino Fundamental, porém em muitas unidades da federação os municípios assumem a maioria das matrículas nas séries iniciais do Ensino Fundamental. É o caso de Santa Catarina. Além disso, a legislação do Fundeb determina que as receitas redistribuídas por esse fundo contemplem apenas essas responsabilidades. Assim, o governo estadual ao não prestar o atendimento da etapa e paulatinamente deixar de atender o seguimento, devido à intensa municipalização ocorrida desde meados dos anos 1990, passa a prescindir de profissionais com a formação de Ensino Médio - Magistério.

Em uma relação mais direta com o tema deste artigo, importa ainda destacar que a lei do piso, uma vez implementada pelo governo estadual, alcançaria basicamente o vencimento inicial que é o da carreira e os outros vencimentos desse reduzido número de profissionais do magistério, já que, não custa lembrar, ela estabeleceu um patamar mínimo de vencimento para professores com formação de Ensino Médio, na modalidade Normal, com 40 horas de jornada de trabalho semanais. O que significa dizer que os vencimentos da grande maioria 
dos profissionais do magistério estadual que, como visto, encontra-se em patamares superiores da carreira, só serão afetados se a aplicação do piso sobre o vencimento inicial repercutir ao longo da estrutura da carreira, de acordo com as atuais proporções entre os vencimentos nas classes e entre os níveis e subníveis. Isso será abordado mais adiante.

O valor dos vencimentos dos profissionais do magistério estadual passou por várias alterações desde 1995 até 2014. O Gráfico 1 oferece uma síntese da trajetória especificamente dos vencimentos iniciais relativos a cada nível de formação da carreira estadual entre 1995 e 2014, cujos valores estão atualizados para reais de dezembro de 2014, de acordo com o Índice Nacional de Preços ao Consumidor (INPC), do Instituto Brasileiro e Geografia e Estatística (IBGE). Os vencimentos seguem sendo desvalorizados até 2004, quando atingem seu menor poder aquisitivo diante da inflação do período, a despeito das reposições em 2001 e 2003. Em seguida, irão apresentar recuperação importante em 2007, com a incorporação de vários abonos, mas só irão repor os patamares de 1995 com o cumprimento da lei do PSPN em 2011, embora os vencimentos dos níveis mais elevados de formação tenham sido mitigados e a carreira desestruturada e achatada ${ }^{10}$, como é evidenciado no gráfico. Nos anos finais da trajetória é possível constatar o achatamento da carreira entre a formação de Ensino Médio-Magistério e de Pós-Graduação-Especialização.

\section{Gráfico 1 - Trajetória do vencimento inicial dos profissionais do magistério com formação de Ensino Médio, Graduação, Especialização, Mestrado e Doutorado e o PSPN - 1995 - 2014.}

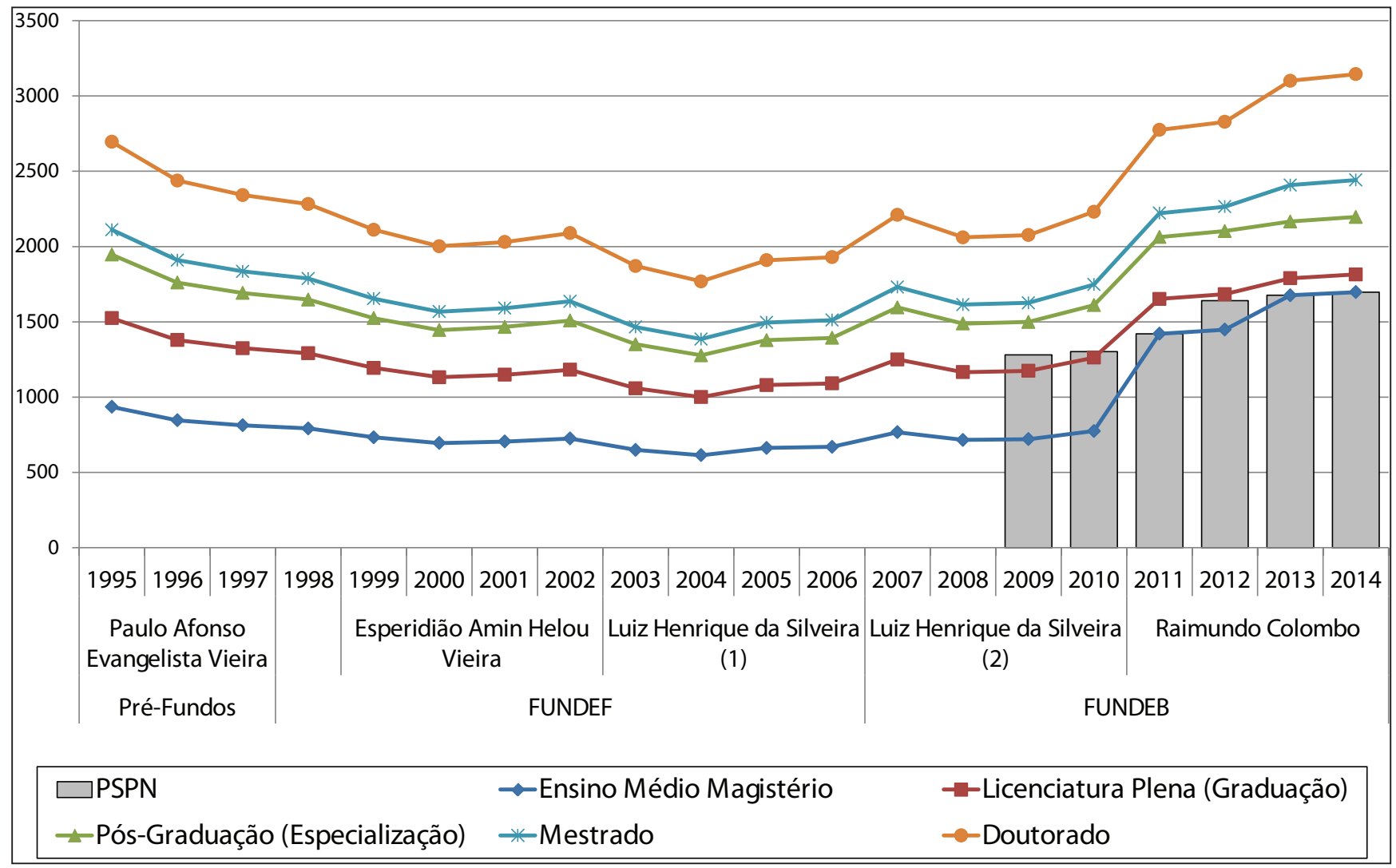

Fonte: Os autores com base em Santa Catarina (2009; 2011a; 2011b; 2011c; 2013; 2014).

Valor real atualizado para reais de dezembro de 2014 pelo INPC/IBGE.

100 governo estadual utiliza a expressão "compactada", como forma de atenuar o impacto das medidas que desestruturaram a carreira. A esse respeito (em dezembro de 2015), tramita na Assembleia Legislativa do Estado de Santa Catarina projeto de lei que objetiva a "descompactação" da carreira. 
Portanto, somente no governo de Raimundo Colombo (2011-2014) é que ocorrerão alterações substanciais nos vencimentos, por força do julgamento final com confirmação da constitucionalidade da lei do piso pelo STF, seguida de imediata, forte e ampla mobilização e paralisação do magistério estadual ${ }^{11}$. Porém, o cumprimento da lei com o vencimento inicial sendo elevado para $\mathrm{R} \$ 1.187,00$ foi acompanhado da desestruturação do plano de cargos e carreira (SANTA CATARINA, 1992) e do achatamento ${ }^{12}$ dos valores dos vencimentos das classes e níveis superiores. Várias regras e critérios de carreira foram modificados e algumas gratificações foram extintas e incorporadas ao vencimento, de forma que o governo atenuou o impacto financeiro das alterações (SANTA CATARINA, 2011b; 2013). Em 2012, o governo deixa de cumprir a lei do piso quando o valor estabelecido nacionalmente alcançou $\mathrm{R} \$ 1.451,75$.

A desestruturação e o achatamento da carreira foram possibilitados pela revogação do dispositivo que determinava a existência de um percentual de 3\% entre os valores dos vencimentos das referências da tabela de vencimentos do magistério (SANTA CATARINA, 2011b). A dispersão ${ }^{13}$ entre os vencimentos inicial e final foi anulada ou substancialmente reduzida. Nos subníveis de cada formação da carreira a dispersão que era originalmente de 38\% foi anulada nos níveis de formação de Ensino Médio-Magistério e Graduação Licenciatura Curta,em que em todas as classes os vencimentos foram equiparados ao valor do piso. No nível relativo à Graduação-Licenciatura Plena a dispersão foi reduzida para $29 \%$. Como resultado, a dispersão geral da carreira, entre os vencimentos inicial (relativo à classe $1 \mathrm{~A}$ da formação de Ensino Médio-Magistério) e final (relativo à classe 12G da formação de Doutorado), foi reduzida de $188 \%$ para apenas $85 \%$.

Tendo em vista a composição do quadro do magistério (Tabelas 1 e 2) vai-se constatar, portanto, que um número reduzido de profissionais do quadro efetivo, enquadrados nos subníveis do Ensino MédioMagistério, foi beneficiado pelo piso. Os milhares de professores ACT foram os maiores beneficiados pelo cumprimento do piso, pois seus vencimentos, fixados com base no valor do vencimento inicial do primeiro subnível da formação de Graduação-Licenciatura Plena, foram reajustados em 39\% em 2011. A Tabela 3 mostra os reajustes de cada classe (referências) em relação aos valores vigentes em 2010, decorrentes do cumprimento do PSPN, em que se constata que praticamente dobrou o valor do vencimento inicial da carreira, com um reajuste de $95 \%$. No subnível 10, em que se encontra a maioria dos profissionais do magistério, os reajustes nas referências estiveram entre 34 e $36 \%$. 110 magistério estadual promoveu forte paralisação das aulas por mais de doismeses após a decisão do STF sobre a lei do PSPN, com ampla participação
dos ACT, e conquistou apoio importante da opinião pública catarinense, o que forçou o governo a implementar a lei do piso.

12 É elevado substancialmente o valor dos vencimentos do início da carreira mas são anuladas e contidas a elevação dos valores dos vencimentos das classes e dos níveis superiores.

13 Segundo Dutra Jr. et al dispersão é " a distância entre a menor e a maior remuneração que correspondem, respectivamente, ao inicio e ao final da carreira de uma determinada categoria profissional” (2000, p. 131). 
Tabela 3 - Percentuais de reajuste nas referências da tabela de vencimentos do magistério estadual de 2011.

\begin{tabular}{|ccccccccc|}
\hline \multirow{2}{*}{ HABILITAÇÃO } & \multirow{2}{*}{ NÍVEL } & \multicolumn{7}{c|}{ R E F E R Ê N C I A S } \\
\cline { 3 - 9 } & & $\mathrm{A}(01)$ & $\mathrm{B}(02)$ & $\mathrm{C}(03)$ & $\mathrm{D}(04)$ & $\mathrm{E}(05)$ & $\mathrm{F}(06)$ & $\mathrm{G}(07)$ \\
\hline \multirow{2}{*}{ ENSINO MÉDIO } & 1 & 1,95 & 1,90 & 1,84 & 1,80 & 1,75 & 1,70 & 1,66 \\
MAGISTÉRIO & 2 & 1,80 & 1,75 & 1,70 & 1,66 & 1,62 & 1,58 & 1,54 \\
& 3 & 1,67 & 1,66 & 1,61 & 1,57 & 1,56 & 1,51 & 1,47 \\
GRADUAÇÃO & 4 & 1,57 & 1,56 & 1,51 & 1,47 & 1,43 & 1,40 & 1,39 \\
LICENCIATURA & 5 & 1,47 & 1,43 & 1,40 & 1,39 & 1,39 & 1,39 & 1,38 \\
CURTA & 6 & 1,39 & 1,39 & 1,39 & 1,38 & 1,38 & 1,38 & 1,37 \\
GRADUAÇÃO & 7 & 1,39 & 1,39 & 1,38 & 1,38 & 1,38 & 1,37 & 1,37 \\
LICENCIATURA & 8 & 1,38 & 1,38 & 1,37 & 1,37 & 1,37 & 1,36 & 1,36 \\
PLENA & 9 & 1,37 & 1,37 & 1,36 & 1,36 & 1,36 & 1,35 & 1,35 \\
PG ESPECIALIZAÇÃO & 10 & 1,36 & 1,36 & 1,35 & 1,35 & 1,35 & 1,34 & 1,34 \\
PG - MESTRADO & 11 & 1,35 & 1,35 & 1,34 & 1,34 & 1,34 & 1,33 & 1,33 \\
PG - DOUTORADO & 12 & 1,34 & 1,34 & 1,33 & 1,33 & 1,33 & 1,32 & 1,32 \\
\hline
\end{tabular}

Fonte: Os autores com base em Santa Catarina (2010; 2011b).

O não estabelecimento de um percentual mínimo na dispersão da carreira, como consta na Resolução do CNE n 03/97 não incluído na atual lei do piso e na Resolução n 02/09 do CNE, permitiu a desestruturação da carreira do magistério em Santa Catarina.

Por fim, convém acrescentar que o conjunto de medidas tomadas pelo governo Raimundo Colombo atenuou o impacto financeiro das despesas com os vencimentos valorizados que resultou do cumprimento do PSPN. O Gráfico 2 mostra que o total de despesas com os vencimentos do magistério que vinha sendo mantido próximo dos $R \$ 40$ milhões até 2010 , salta para perto de $R \$ 65$ milhões de 2011 em diante. Nesse aumento, as despesas com o vencimento dos ACT cresceu 206\% passando a ocupar 33\% do total das despesas em 2011 diante dos $26 \%$ até o ano anterior, enquanto a soma dos vencimentos dos efetivos cresceu 49\%, reduzindo sua participação na despesa total de 74 para $67 \%$. 
Gráfico 2 - Despesas com o vencimento dos profissionais do magistério - 2006 - 2013

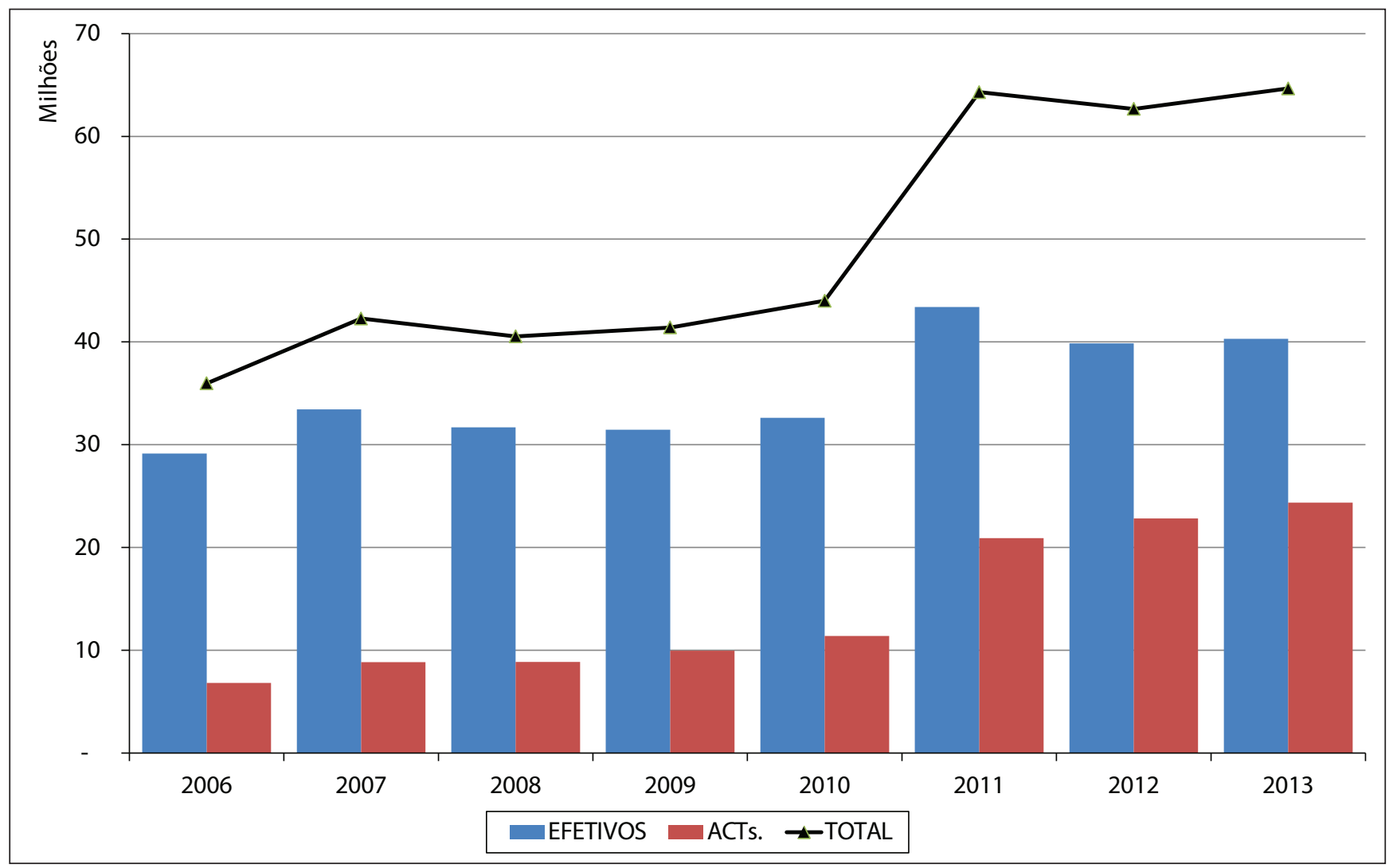

Fonte: Os autores com base em Santa Catarina, 2014.

Valores atualizados para dezembro de 2014 (INPC-IBGE).

\section{Conclusões}

Os vencimentos dos profissionais do magistério da educação básica da rede estadual de ensino sofreram significativas alterações entre 1995 e 2014. Na maior parte do período em que esteve em vigência a política de fundos com dispositivos que obrigavam a aplicação de grande parcela das suas receitas na remuneração dos profissionais da educação, a trajetória dos vencimentos nos anos iniciais do período seguiu em desvalorização, permaneceu estagnada em baixos valores nos anos intermediários e somente com o cumprimento da lei do piso, após a confirmação da sua constitucionalidade pelo STF, ocorreu a valorização e ganho real de valor.

Os milhares de professores ACT foram os mais beneficiados em seus vencimentos pelo cumprimento da lei do piso, em virtude destes vincularem-se ao valor do vencimento inicial do nível de carreira dos profissionais com formação em Graduação com Licenciatura Plena. Porém, os vencimentos da maioria dos profissionais efetivos que se encontram em patamares próximos ao topo da carreira foram reajustados em proporções muito menores. Isso, em função das alterações promovidas no plano de carreira que provocaram um aumento substancial nas despesas totais com os vencimentos dos profissionais do magistério de um modo geral.

Pode-se deduzir disso que as alterações foram definidas deliberadamente para conter o aumento das despesas. Tais medidas achataram a dispersão percentual entre os vencimentos e desestruturaram o plano de carreira e remuneração do magistério estadual, o que revela que o discurso oficial de valorização do magistério na prática não se concretiza.

Por fim, convém acrescentar que esse achatamento pode implicar no descumprimento da meta 17 do PNE e da meta de mesmo número do Plano Estadual de Educação as quais objetivam a equiparação do rendimento médio dos profissionais do magistério ao dos demais profissionais com escolaridade equivalente. 


\section{Referências}

ABICALIL, C. A. Piso Salarial Constitucional, legítimo, fundamental. Revista Retratos da Escola, Brasília, v. 2, n. 2-3, p. 67-80, jan./dez. 2008. Disponível em http://www.esforce.org.br/index.php/semestral/article/view/125/228. Acesso em 12 dez. 2015.

ARELARO, L. R. Fundef: uma avaliação preliminar dos dez anos de sua implantação. Disponível em http://30reuniao.anped.org.br/trabalhos/GT05-3866--Int.pdf. Acesso em 12 dez, 2015.

BORGES, A. M. Professor ACT, descartável ou imprescindível? Perspectiva, v. 13, n. 23. 1995. Disponível em https://periodicos.ufsc.br/index.php/perspectiva/article/view/10636. Acesso em 12 dez. 2015.

BASSI, M. E.; DEBOVI, A.; SANDRINI, N. M. S. Carreira e remuneração do magistériopúblico da educação básica no sistemade ensino estadual de Santa Catarina. Educação em Foco. Vol. 15, n 19, junho 2012, p. 57 80. Disponível em http://www.uemg.br/openjournal/index.php/educacaoemfoco/article/view/249/218. Acesso em 21 jan. 2012.

GIL, J. Remuneração de professores de escolas públicas no contexto do Fundeb e do PSPN. In: GOUVEIA, A. B.; PINTO, J. M.; FERNANDES, M. D. Financiamento da educação no Brasil - os desafios de gastar 10\% do PIB em dez anos. Campo Grande: Oeste, 2015.

BRASIL.Constituição (1988). Constituição da República Federativa do Brasilde 1988. 18. ed. São Paulo. Saraiva, 1998.

Emenda Constitucional $\mathbf{n}^{\circ}$ 14, de 12 de setembro de 1996. Modifica os arts. 34, 208, 211 e 212 da Constituição Federal e dá nova redação ao art. 60 do Ato das Disposições constitucionais Transitórias. 1996a. Diário Oficial da União, Brasília, 13set. 1996.

Lei $\mathbf{n}^{\circ}$ 9.394, de 20 de dezembro de 1996. Estabelece as diretrizes e bases da educação nacional. 1996b. Diário Oficial da União, Brasília, 23 dez. 1996.

Lei $\mathbf{n}^{\circ} \mathbf{9 . 4 2 4}$, de 24 de dezembro de 1996. Dispõe sobre o Fundo de Manutenção e Desenvolvimento do Ensino Fundamental e de Valorização do Magistério, na forma prevista no art. 60, § $7^{\circ}$, do Ato das Disposições Constitucionais Transitórias, e dá outras providências. 1996c. Disponível em: http://www.planalto.gov.br/ccivil_03/ leis/19424.htm. Acesso em: 9 set. 2014.

Lei $\mathrm{n}^{\circ}$ 10.172, de 09 de junho de 2001. Aprova o Plano Nacional de Educação e dá outras providências. Diário Oficial da União, Brasília, 10 jan. 2001.

Emenda Constitucional $\mathbf{n}^{\circ}$ 53, de 19 de dezembro de 2006. Dá nova redação aos arts. $7^{\circ}, 23,30$, 206, 208, 211 e 212 da Constituição Federal e ao art. 60 do Ato das Disposições Constitucionais Transitórias. 2006. Disponível em: http://www.planalto.gov.br/ccivil_03/Constituicao/Emendas/Emc/emc53.htm. Acesso em: 1 out. 2013.

Lei $\mathbf{n}^{\circ}$ 11.494, de 20 de julho de 2007. Regulamenta o Fundo de Manutenção e Desenvolvimento da Educação Básica e de Valorização dos Profissionais da Educação - FUNDEB, de que trata o art. 60 do Ato das Disposições Constitucionais Transitórias; altera a Lei n 10.195, de 14 de fevereiro de 2001; revoga dispositivos das Leis no 9.424, de 24 de dezembro de 1996, 10.880, de 9 de junho de 2004, e 10.845, de 5 de março de 2004; e dá outras providências. 2007. Disponível em: http://www.planalto.gov.br/ccivil_03/_ato2007-2010/2007/ Lei/L11494.htm. Acesso em: 1 out. 2013.

Lei $\mathbf{n}^{\circ} \mathbf{1 1 . 7 3 8}$, de 16 de julho de 2008. Regulamenta a alínea "e" do inciso III do caput do art. 60 do Ato das Disposições Constitucionais Transitórias, para instituir o piso salarial profissional nacional para os profissionais do magistério público da educação básica. 2008. Disponível em: http://www.planalto.gov.br/ ccivil_03/_ato2007-2010/2008/lei/l11738.htm. Acesso em: 9 set. 2014.

Lei 13.005, de 25 de junho de 2014. Aprova o Plano Nacional de Educação - PNE e dá outras providências. Diário Oficial da União, Brasília, 26 jun. 2014. 
Conselho Nacional de Educação. Parecer CNE/CEB 02, de 26 de fevereiro de 1997. Diretrizes para a carreira e remuneração do magistério público. 1997a. Disponível em http://portal.mec.gov.br/conselhonacional-de-educacao/atos-normativos--sumulas-pareceres-e-resolucoes/323-secretarias-112877938/orgaosvinculados-82187207/13255-parecer-ceb-1997. Acesso em 09 dez. 2015.

Resolução CNE/CEB n 3, de 8 de outubro de 1997. Fixa Diretrizes para os Novos Planos de Carreira e de Remuneração para o Magistério dos Estados, do Distrito Federal e dos Municípios. 1997b. Disponível emhttp://portal.mec.gov.br/conselho-nacional-de-educacao/atos-normativos--sumulas-pareceres-eresolucoes/323-secretarias-112877938/orgaos-vinculados-82187207/13205-resolucao-ceb-1997.Acessoem 09 dez. 2015.

Resolução CNE/CEB n² 2, de 28 de maio de 2009. Fixa as Diretrizes Nacionais para os Planos de Carreira e Remuneração para osProfissionais do Magistério da educação básica pública. 2009. Disponível em http://portal.mec.gov.br/dmdocuments/resolucao_cne_ceb002_2009.pdf.Acesso em 12 dez. 2015.

Supremo Tribunal Federal. Ação direta de inconstitucionalidade $n^{\circ} 4.167$, de 29 de outubro de 2008. Brasília, 2011. Disponível em: http://www.stf.jus.br/portal/geral/verPdfPaginado.asp?id=626497\&tipo=AC \&descricao=Inteiro\%20Teor\%20ADI\%20/\%204167. Acesso em: 3 ago. 2014.

CAMARGO, R. B. et al. Financiamento da educação e remuneração docente: um começo de conversa em tempos de piso salarial. 2009. RBPAE, v. 25, n. 2. Disponível em http://seer.ufrgs.br/rbpae/article/view/19501. Acesso em 10 dez. 2015.

CONGRESSO NACIONAL DE EDUCAÇÃO, 1997, Belo Horizonte. Comissão Organizadora. Plano Nacional de Educação: Proposta da Sociedade Brasileira. Belo Horizonte: II CONED, 1997. Disponível em: http://www.fedepsp. org.br/documentos/PNE\%20-\%20proposta\%20da\%20sociedade\%20brasileira.pdf. Acesso em: 10 dez. 2015

DAVIES, N. O Fundef e as verbas da educação. São Paulo: Xamã, 2001.

Fundeb, a redenção da educação básica? Campinas: Autores Associados, 2008.

DUTRA JR, A. F. et al.Plano de Carreira e Remuneração do Magistério Público: LDB, FUNDEF, Diretrizes nacionais e nova concepção de carreira. FUNDESCOLA/MEC, 2000.

MARTINS, P. S. Fundeb, federalismo e regime de colaboração. Campinas: Autores Associados, 2011.

MONLEVADE, J.; FERREIRA, E. B. O Fundef e seus pecados capitais. 2 ed. Ceilândia, 1998.

OLIVEIRA, D. A. O trabalho docente na América Latina: identidade e profissionalização. Revista Retratos da Escola, Brasília, v.2, n.2-3, p.29-39, jan./dez.2008.

OLIVEIRA, R. P. O financiamento da educação. In: ADRIÃO, Theresa (orgs.). Gestão, financiamento e direito à educação. 3 ed. São Paulo: Xamã, 2007.

SANTA CATARINA. Lei Complementar Promulgada n 1.139, de 28 de outubro de 1992. Dispõe sobre cargos e carreiras do Magistério Público Estadual estabelecem nova sistemática de vencimentos, institui gratificações e dá outras providências. Disponível em http://www.sed.sc.gov.br/secretaria/documentos/doc_download/1122lei-complementar-promulgada-no-1139-1992.Acesso em 12 dez. 2015.

Tabelas de vencimentos do magistério de educação básica de 1994 a 2009. 2009. Florianópolis: SED (mimeo).

Lei Complementar ${ }^{\circ}$ 539, de 18 de julho de 2011. Modifica o valor de vencimento, altera gratificações, absorve e extingue vantagens pecuniárias dos membros do Magistério Público Estadual, ativos e inativos, e estabelece outras providências. 2011b. Disponível em http://200.192.66.20/ALESC/PesquisaDocumentos.asp. Acesso em 12 dez. 2015.

Lei $\mathbf{n}^{\circ}$ 15.695, de 21 de dezembro de 2011. Dispõe sobre a data-base para fins de revisão geral anual da remuneração e subsídio dos servidores públicos civis e militares estaduais, ativos, inativos e pensionistas do Poder Executivo e estabelece outras providências. 2011c. Disponível em http://200.192.66.20/ALESC/ PesquisaDocumentos.asp. Acesso em 12 dez. 2015. 
SANTA CATARINA. Lei Complementar n $^{\circ}$ 592, de 20 de março de 2013.Modifica o valor de vencimento dos membros do Magistério Público Estadual, ativos e inativos, e estabelece outras providências.2013. Disponível em http://200.192.66.20/ALESC/PesquisaDocumentos.asp. Acesso em 12 dez. 2015.

Lei Promulgada $n^{\circ} 16.360$, de16 de abril de 2014. Fixa os valores de vencimento dos membros do Magistério Público Estadual e estabelece outras providências. 2014. Disponível em http://200.192.66.20/ALESC/ PesquisaDocumentos.asp. Acesso em 12 dez. 2015.

Plano estadual de educação - 2015 - 2014. Versão preliminar. Florianópolis, 2015. Disponível em http://www.sed.sc.gov.br/secretaria/plano-estadual-de-educacaosc-versao-preliminar. Acesso em 12 dez. 2015. Secretaria do Estado da Educação. Diretoria do Desenvolvimento Humano. Despesa financeira de pessoal do quadro do magistério público estadual. 2011a.Florianópolis: SED (Arquivo Eletrônico).

Quantitativo de professores efetivos por nível/referência. 2011b. Florianópolis: SED (Arquivo Eletrônico).

SANTA CATARINA. Secretaria do Estado da Fazenda. Relação de servidores. 2014. Disponível em http:// www.transparencia.ciasc.sc.gov.br/Acessolnformacao/(S(1hl3hpatxdz5mekk22nivixz))/Paginalnicial.aspx. Acesso em 10 dez. 2015.

SILVEIRA, A. D. O judiciário brasileiro e a política educacional: questionamento da lei do piso nacional para o magistério no Supremo Tribunal Federal. Cadernos de Pesquisa: pensamento educacional. Curitiba, v. 8, n. 19, págs. 219-250, mai./ago., 2013.

SINDICATO DOS TRABALHADORES EM EDUCAÇÃO DA REDE PÚBLICA DE ENSINO NO ESTADO DE SANTA CATARINA. Valores salariais a partir de agosto de 2010 (4,277\%) 40 horas semanais Tabela Consolidada. 2010.

Recebido em Outubro de 2015 | Aprovado em Dezembro de 2015 